\title{
COMENTÁRIOS PARA UMA EDUCAÇÃO ESTÉTICA DA HUMANIDADE
}

\author{
Ive Braga ${ }^{1}$
}

\begin{abstract}
Resumo
O presente ensaio tem como objetivo apresentar elementos que permitam promover reflexões acerca da formação do indivíduo na sociedade administrada, sua relação com os modos de produção e circulação da cultura, seus processos, instituições, possibilidades e limites. Para tanto, pauta-se na revisão bibliográfica para exploração de conceitos teóricos de autores da primeira geração da Escola de Frankfurt - em especial Herbert Marcuse, Theodor W. Adorno, Max Horkheimer e Walter Benjamin - para analisar: o processo de produção material sob o qual a cultura se desenvolve; a formação do indivíduo sob a égide desta cultura; as transformações dos estímulos artísticos e suas consequências para a percepção sensorial; o papel das instituições no desenvolvimento e/ou ajustamento do espírito e os benefícios e armadilhas da correlação entre distintas áreas do saber para produção de conhecimento científico. Abstendo-se da necessidade de indicar resultados e conclusões pontuais, esta análise visa promover debates sobre os limites e alternativas possíveis para o enfrentamento da realidade objetiva com vistas para uma educação estética de humanidade.
\end{abstract}

Palavras-chave: Arte, cultura, ciência, educação estética da humanidade.

\section{COMMENTS FOR AN AESTHETIC EDUCATION OF HUMANITY}

\begin{abstract}
The objective of this essay is present theoretical elements to promote reflections about the individual formation in the administered society, your relationships with the modes of production and circulation of culture, processes, institutions, possibilities and limits. To accomplish this job, this analysis explores the theoretical concepts of authors from the first generation of the Frankfurt School, in particular Herbert Marcuse, Theodor W. Adorno, Max Horkheimer and Walter Benjamin. The main notions explored are: the material production process under which culture develops and their influences on the individual formation, the transformations of artistic stimuli and their consequences for sensory perception; the role of institutions in the development and / or adjustment of the spirit and the benefits and harms of the correlation between different areas of knowledge for the production of scientific knowledge. Abstaining from the need to indicate specific results and conclusions, this analysis aims to promote debates about the limits and possible alternatives for confront the objective reality aiming an aesthetic education of humanity.
\end{abstract}

Keywords: Art, culture, science, aesthetic education of humanity.

\section{Introdução}

O presente ensaio tem como objetivo apresentar elementos que permitam promover reflexões acerca da formação do indivíduo na sociedade administrada, sua relação com a cultura, seus processos, instituições, possibilidades e limites. Para fim de cotejar

1 Pedagoga, Psicanalista, Doutora em Educação: História, Política, Sociedade pela Pontifícia Universidade Católica de São Paulo, Docente do Instituto Singularidades, Pesquisadora do Grupo de Pesquisa Teoria Crítica, Formação e Cultura (habilitado pela PUC-SP e vinculado ao Diretório dos Grupos de Pesquisa do Conselho Nacional de Pesquisa - CNPq). Professora-Orientadora convidada do Instituto Singularidades. E-mail: ivebraga@gmail.com 
formulações teóricas dos autores de primeira geração da Escola de Frankfurt - Herbert Marcuse, Theodor W. Adorno, Max Horkheimer e Walter Benjamin - a proposta baseada na revisão bibliográfica tem como objetivo explorar algumas noções teóricas, nas quais a recolha permitiu a organização da argumentação apresentada em cinco tópicos correlacionados entre si. O primeiro tópico: 1) A sociedade, a política e o cultivo do espírito é focalizado o processo de produção material sob o qual a cultura se desenvolve. No segundo: 2) A indústria da cultura e a regressão dos sentidos, analisa-se a formação do indivíduo sob a égide desta cultura que tende a acarretar a regressão dos sentidos. No terceiro: 3) A formação e as instituições, observa-se o papel das instituições no desenvolvimento e/ou ajustamento do espírito. No quarto tópico, denominado: 4) A ciência e a correlação entre distintas áreas do conhecimento, desenvolve-se um debate que coloca em evidência aspectos positivos e negativos da interdisciplinaridade e, por fim, no quinto e último tópico: 5) Notas para uma educação estética da humanidade, são instigadas - sem a obrigação do apontamento de conclusões pontuais - reflexões que permitem apontar limites e alternativas possíveis para tecer a crítica da realidade objetiva com vistas a uma educação estética de humanidade. Tendo exposto a organização formal do ensaio, seguem os tópicos que formam sua totalidade:

\section{1) A sociedade, a política e o cultivo do espírito}

Iniciar esta argumentação sem levar em conta o processo de produção material sob o qual a cultura se desenvolve seria adentrar a discussão partindo de um equívoco intransponível. A fim de evitar este equívoco - uma vez que os sujeitos são determinados pelo modo de produção material de uma sociedade - a argumentação aqui erigida visa explorar as tensões constituintes entre a forma de organização política e econômica do capitalismo tardio e suas consequências no processo de constituição do indivíduo como categoria burguesa.

\footnotetext{
Efetivamente, o mundo do verdadeiro, bom e belo é um mundo "ideal", na medida em que situa além das condições de vida vigentes, além de uma forma da existência em que a maioria dos homens trabalha e passa a vida no comércio de mercadorias e onde só uma pequena camada tem a possibilidade de se ocupar daquilo que vai além da conquista e da garantia das necessidades. (MARCUSE, 1997, p.91).
}

O excerto permite adentrar a discussão proposta tomando como ponto de partida a premissa de que ao mesmo tempo que o capital abriu caminho para o desenvolvimento de uma sociedade de abundância, impôs também uma cisão entre a vida objetiva e a felicidade

\begin{tabular}{|l|l|l|l|l|}
\hline Qevista Dialectus & Ano 9 & n. 19 & Agosto - Dezembro 2020 & p. $149-161$ \\
\hline
\end{tabular}


idealizada. As benesses do cultivo do espírito, portanto, ficam restritas apenas a uma pequena parcela da população; parcela esta que pode gozar dos benefícios de uma vida projetada para além da manutenção das necessidades básicas de sobrevivência. Em contrapartida, às pessoas que se encontram obrigatoriamente voltadas à manutenção das necessidades - e que representam maioria substancial - não resta oportunidade, tempo ou disposição para participarem do acesso aos valores espirituais. Este desvio que, além assumir a roupagem de privilégio, evidencia um deslocamento dos valores espirituais para um plano a parte à cultura que revela, dentre outras coisas, uma diferenciação cortante entre indivíduos, condicionandoos à distinção de classes. A despeito desta ponderação, Marcuse acrescenta:

\footnotetext{
Conforme sua essência, a verdade de um juízo filosófico, a bondade de uma ação moral, a beleza de uma obra de arte, devem afetar a todos, se referir a todos, comprometer a todos. Independente do sexo e origem, sem referência a sua posição no processo produtivo, esses indivíduos precisam se subordinar aos valores culturais. Precisam assumi-los em sua vida, facultando-lhes permear e transfigurar sua existência. A "cultura” fornece alma à civilização. (MARCUSE, 1997, p. 95).
}

O caráter progressista da cultura burguesa revela uma contradição: ele enfatiza que a felicidade está ao alcance de todos dependendo agora do esforço e do mérito individual. Porém, em uma sociedade baseada em bens de produção material, o Bom, o Belo e o Verdadeiro passam a se situar além das condições de vida vigente. Tal cisão entre os mundos materiais e espirituais evidenciam o caráter afirmativo da cultura burguesa, que sugere a potencialidade do indivíduo ao mesmo tempo que mantém as condições existentes à medida que transfere para esfera subjetiva o fracasso individual.

O que ocorre pode ser expresso do seguinte modo: quando num filme sentimental ou numa música de mesmo tipo, a audiência toma consciência da avassaladora possibilidade de felicidade, eles ousam confessar a si mesmos o que toda a ordem da vida contemporânea comumente lhes proíbe de admitir, ou seja, que eles não têm efetiva participação na felicidade. (ADORNO e SIMPSON, 1986, p.141).

A cultura burguesa recupera a afirmação da potencialidade de emancipação do individuo, mas, ao mesmo tempo e contraditoriamente, veta tal idealização no plano real. Essa dinâmica mesquinha subordina os valores universais às leis de mercado. Assim, O Bom, Belo, Verdadeiro como valores universais da humanidade ou perdem seu sentido ou ficam à cargo dos privilegiados. De repente, o necessário - como a efetivação de tais valores - transforma-se em supérfluo e o supérfluo - como a organização da existência em função de bases materiais transforma-se em necessário. Como conclusão parcial para que seja possível adentrar a análise

\begin{tabular}{|l|l|l|l|l|}
\hline Q Rovista Dialectus & Ano 9 & n. 19 & Agosto - Dezembro 2020 & p. 149 - 161 \\
\hline
\end{tabular}


de outros elementos no tópico seguinte, pode-se dizer então que, como tendência, a organização capital da existência humana desfigura o indivíduo. Nesses termos, se o mote da existência é, por fim, o mote da organização material da existência, a partir dessa inversão, parece válido questionar qual forma de vida sobre a terra é supérflua e qual forma de vida é a Verdadeiramente necessária.

\section{2) A indústria da cultura e a regressão dos sentidos}

Dando continuidade aos argumentos expostos anteriormente, é fundamental apontar também que a arte em si não enobrece objetivamente. Seria ingênuo afirmar que a arte tem o poder espontâneo de libertar o indivíduo de sua subordinação efetiva. Porém, na esfera subjetiva, ou, o reino da alma talvez seja a única esfera resguardada capaz de gerar a transformação partindo do interior. "A beleza da cultura é sobretudo uma beleza interior e pode alcançar o exterior apenas partindo do interior. Seu reino é essencialmente um reino da alma”. (MARCUSE, 1997, p. 103). Assim, a transformação que parte da esfera subjetiva seria o primeiro passo para potencializar a mudança exterior.

Por intermédio do recrutamento da sensibilidade a arte pode atirar o sujeito em direção a si mesmo, para o profundo estágio da qual necessita a atividade de contemplação genuína. A abertura para o mundo sensível proporcionado pela obra de arte sugere o abandono de si mesmo. É nesse instante, na renúncia de si, que se estabelece o elo entre o universal e o particular e no qual se apreende a existência tocante de uma obra. Nesse choque, o potencial político da obra de arte é colocado em questão: se a obra de arte é capaz de mobilizar a sensibilidade e por isso promover a reflexão, em linhas gerais a suspeita que aqui se levanta é que se arte é capaz de impactar, de promover o contato direto entre sujeito e objeto, de implicar no recrutamento da reflexão e da sensibilidade talvez o potencial político e transformador da obra de arte resida na possibilidade da efetivação da experiência mesmo diante das condições objetivas que a impedem.

Uma vez tratado um dos primeiros aspectos que abarcam especificamente os benefícios do cultivo do espírito por intermédio do acesso às obras de arte vale a pena oferecer um contraponto ao debate, uma vez que não se trata de uma discussão potencialmente simplória:

A cultura superior ainda existe. É mais acessível do que nunca. É lida, vista e ouvida por mais pessoas do que jamais o fora; porém, a sociedade bloqueou há muito tempo

\begin{tabular}{|l|l|l|l|l|}
\hline Q Povista Dialectus & Ano 9 & n. 19 & Agosto - Dezembro 2020 & p. $149-161$ \\
\hline
\end{tabular}


os domínios espirituais dentro dos quais essa cultura poderia ser entendida em seu conteúdo cognitivo e em sua verdade determinada. (MARCUSE, 1998, p.159-160)

O excerto permite constatar que o simples acesso à cultura não garante que a arte seja capaz de conduzir o indivíduo à experiência, à reflexão, a questionar ou resistir às mazelas sociais. A facilitação do acesso aos produtos culturais possibilitado pela indústria cultural, importante noção desenvolvida por HORKHEIMER e ADORNO (2011) é ambivalente, ou seja, é positiva e negativa: possibilitou à massa o acesso antes restrito a uma pequena parcela da população ao mesmo tempo que o seu fácil acesso por si só não se tornou capaz de recrutar as esferas sensíveis e cognitivas que poderiam caracterizar a experiência. A indústria cultural, que se apropria, reproduz e transforma a cultura em produtos e mercadorias liquidou a existência única e transformadora das obras de arte.

A esse respeito, Benjamin acrescenta à análise uma importante consideração:

No interior de grandes períodos históricos, a forma de percepção das coletividades humanas se transforma ao mesmo tempo que seu modo de existência. O modo pelo qual se organiza a percepção humana, o meio em que ela se dá, não é apenas condicionado naturalmente, mas também historicamente. (BENJAMIN, 1994, p.169).

O modo de percepção sensível dos homens sofre alterações que são decorrentes das alterações das condições materiais na cultura. Dessa maneira, não se trata apenas de refletir sobre as alterações no processo de produção material e na forma de circulação dos bens da cultura. Se o modo de produção cultural se transforma ocorre também a transformação da forma e conteúdo estético das obras de arte. Nesse ínterim, cada vez menos disponível à recepção de estímulos sensíveis elaborados ocorre, por sua vez, a deterioração dos receptáculos sensoriais que captariam esses estímulos e, assim, a percepção humana, reduzida a cada dia mais ao achatamento sensível e sensorial, recrudesce. A esse respeito, vale acrescentar uma ponderação de Adorno que estabelece um paralelo entre a forma de produção cultural e o ajustamento dos indivíduos:

A renúncia ao sonhar desses compositores é um índice de que ouvintes estão prontos a substituir o sonhar pelo ajustamento à crua realidade, colhendo um novo prazer a partir de sua aceitação do desagradável. (ADORNO e SIMPSON, 1986, p.139).

Ocorre assim, não apenas o ajustamento dos objetos da cultura, mas também dos sujeitos que a compõem. Novamente tomando a música como exemplo, Adorno (1996) afirma que a nova forma de produção musical baseada em padrões estandardizados acarreta a regressão da audição. Parece que a dominação atinge então todas as instâncias da constituição

\begin{tabular}{|l|l|l|l|l|}
\hline Q Rovista Dialectus & Ano 9 & n. 19 & Agosto - Dezembro 2020 & p. $149-161$ \\
\hline
\end{tabular}


humana: psíquica, espiritual e também física. A adaptação à música de máquina implica necessariamente uma renúncia aos seus próprios sentimentos humanos e, ao mesmo tempo, um fetichismo da máquina tal que seu caráter instrumental se torna obscurecido. (ADORNO e SIMPSON, 1986, p.140). Se, de fato, ocorre uma regressão da percepção, dos sentidos, ou seja, se há um entrave, um bloqueio na porta de entrada que conecta a subjetividade à objetividade; então o modo como o homem percebe, como se relaciona e como interage com a cultura e seus pares torna-se desfigurada. Em linhas gerais, a arte, que vem sofrendo transformações históricas em sua forma e conteúdo ao que se refere ao tipo de estímulo produzido, quando transfigura um estímulo de difícil compreensão em algo palatável, reduz a possibilidade de ampliação dos sentidos. Quando qualquer estímulo artístico/sensível é instrumentalizado ele passa a ser meio quando deveria ter fim em si mesmo. É nesse processo de achatamento formal que os estímulos sensíveis abdicam de estimular a potencialidade sensorial em troca da repetição padrão daquilo que agrada pela estandardização. E assim, o potencial da expressão artística como rumo para a formação e emancipação se converte em um veículo para adaptação, para normatização, para a padronização e nivelamento das diferenças.

\section{3) A formação e as instituições}

Nos termos frankfurtianos, entende-se que: “[...] a formação nada mais é do que a cultura tomada pelo lado de sua apropriação subjetiva ${ }^{2} "$. (ADORNO, 1966). Tomando o conceito de formação em sua amplitude a partir do entendimento de que a formação do indivíduo se desenvolve via mediação da cultura, pode-se considerar que a inter-relação indissociável entre as noções de cultura e formação constituem os elementos fundantes desta reflexão. Por esta razão pretende-se aprimorar a observância acerca do complexo processo que caracteriza a formação do indivíduo na sociedade burguesa e sua relação com as instituições, aqui entendidas como as responsáveis pela mediação cultura-indivíduo. Não obstante, as instituições, como tendência e de modo paradoxal, investem em práticas que resultam tanto na potencialização quanto na aniquilação do espírito.

Faz necessário, portanto, refletir a respeito da função social das instituições. Assim, se admitirmos o papel das mesmas na função de conformação às mazelas sociais, à ordem estabelecida e ao preparo para o mundo do trabalho alienado, com certeza abordaremos o

${ }^{2}$ Tradução livre para o português do texto em espanhol.

\begin{tabular}{|l|c|c|c|c|}
\hline Renita Cialectus & Ano 9 & n. 19 & Agosto-Dezembro 2020 & p. $149-161$ \\
\hline
\end{tabular}


problema de forma menos ingênua. É evidente que se deva olhar, também, para as instituições como lócus geradores de conhecimento com potenciais para investimento na fortificação do indivíduo e, por conseguinte, como capazes de favorecer a emancipação. Mas, certamente a crítica às instituições sociais não seria exitosa se ignorasse qualquer um dos lados dessa questão. Então, para fim de ampliar a exploração proposta, considera-se relevante sublinhar ambos os aspectos - progressivos e regressivos - que orientam o processo de apropriação da cultura que caracteriza a formação do indivíduo na sociedade administrada. O pretendido, por consonância, não é enaltecer tampouco macular o papel das instituições no processo de formação do indivíduo, mas sim examinar as tensões, os conflitos e antíteses do processo de formação do indivíduo no âmbito da uma dinâmica social complexa, e por que não dizer, antagônica.

De acordo com Marcuse (1998, p. 161):

[...] a validade histórica de ideias, como liberdade, igualdade, justiça, indivíduo, subsistia precisamente em seu conteúdo ainda irrealizado - pois não podiam ser relacionadas com a realidade existente, que não as conformava nem as poderia confirmar, porque eram negadas precisamente pelo funcionamento daquelas instituições que deveriam realizar essas ideias.

As instituições, que deveriam primar pela busca de valores superiores de modo a enobrecer os indivíduos, acabam militando contra seus próprios objetivos: abrem mão da formação em favor de interesses marcadamente voltados para a competição, o lucro, a dominação do outro, em nome da formação para o trabalho.

[...] a pacificação da luta pela existência, a redefinição do trabalho como livre realização das necessidades e das disposições dos homens pressupõem, não apenas instituições essencialmente diferentes, mas também homens essencialmente diferentes - homens que já não precisam ganhar o seu pão com o trabalho alienado. Essa diferença não pode surgir por si só no quadro restrito das instituições, que são determinadas essencialmente por organizar o trabalho alienado. (MARCUSE, 1998, p. 163).

O nível técnico e tecnológico da sociedade há tempos dispõe de condições suficientes para a libertação do homem, porém a emancipação não ocorreu. O problema não é o trabalho em si, mas o modo de funcionamento das instituições que elide o trabalhador dos meios de produção e transforma o mero trabalho em trabalho alienado. O autor acrescenta: "Essa ausência de felicidade não é metafísica; constitui obra de uma organização social desprovida de razão". (MARCUSE, 1997, p. 130-131). Nesse panorama, a infelicidade não é obra do acaso. É resultado de uma organização social nefasta que envolve diversos setores da

\begin{tabular}{|l|l|l|l|l|}
\hline Qevista Dialectus & Ano 9 & n. 19 & Agosto - Dezembro 2020 & p. 149 - 161 \\
\hline
\end{tabular}


sociedade para gerir organizações que obrigam os indivíduos, quando muito, a viver pela simples manutenção das condições orgânicas de subsistência. As instituições - dentre elas a escola - com a tarefa de normatização da conduta, de formação para o trabalho alienado e para adequação do sujeito à ordem estabelecida adquirem sua parcela de culpa nesse processo que captura os indivíduos desde a mais tenra idade:

\begin{abstract}
Nenhum mecenas individual e privado seria capaz de financiar uma educação que poderia preparar o terreno de uma hierarquia qualitativamente diferente de valores e poderes. Uma tal educação poder-se-ia imaginar talvez como tarefa de um governo que estivesse disposto e fosse capaz de reagir contra as tendências políticas dominantes e propagadas universalmente - uma condição que apenas é preciso formular para revelar seu caráter utópico. (MARCUSE, 1998, p. 165).
\end{abstract}

Qualquer iniciativa qualitativa independente assume o caráter de "geração espontânea" e logo perde sua validade no confronto com a esmagadora realidade. A transformação social depende de uma série de questões que, possivelmente só podem ser alteradas por uma intensa e duradoura luta política. O referido assunto vem ao caso, pois, embora reconheçamos o caráter regressivo das instituições, é preciso admitir que a atividade docente é uma atividade política, que, se bem-intencionada, pode oferecer resultados significativos. Por esta razão não seria conveniente atribuir à escola a culpa de um processo do qual ela é agente, mas, também, vítima. Há de se verificar, na escola, suas fraturas, mas também suas potencialidades. É neste âmbito que parece válido apostar algumas fichas na intersecção entre distintas áreas o conhecimento, tal como a arte e a educação, no que se refere às possibilidades de ampliação das possibilidades de formação.

Considerando esses apontamentos, vale acrescentar a respeito das obras de arte a ponderação de Marcuse (1977, p. 61): “Como mundo fictício, como ilusão, contém mais verdade que a realidade de todos os dias. Pois, esta última é mistificada nas suas instituições e relações, que fazem da necessidade uma escolha e da alienação uma autorrealização”. O poder negativo da arte direciona para um trajeto possível, um caminho mais verdadeiro que o de todos os dias justamente por que não se encontra mistificado e impregnado pela má consciência da vida real. "A lógica interna da obra de arte termina na exigência de outra razão, outra sensibilidade, que desafiam a racionalidade e a sensibilidade incorporadas nas instituições sociais dominantes”. (MARCUSE, 1977, p.19-20). Considerando o exposto, pode-se dizer que a arte exige uma mudança de paradigmas. É justamente por isso que, não por acaso, do ponto de vista social, o artista é sempre o louco, o desajustado, o inadequado. Basta o aparecimento desse tipo de gênio para a escola declarar assumidamente sua inabilidade. E, por consequência

\begin{tabular}{|l|l|l|l|l|}
\hline Qevista Dialectus & Ano 9 & n. 19 & Agosto - Dezembro 2020 & p. $149-161$ \\
\hline
\end{tabular}


- por não saber lidar com o diferente - trata de excluir ou, conformar à força, à "normalidade". Os artistas, sejam eles de prática ou de espírito, são incompreendidos justamente por não aderirem a esta má consciência que insiste em se impor como racional. A arte preconiza a possibilidade de uma experiência autêntica. Uma experiência não determinada, completamente diferente daquela se apresenta como norma: uma experiência racional, sensível, autônoma, emancipada. O impasse entre a arte e a escola está justamente no fato de a escola não estar preparada para este novo mundo, de nobres ideais. E - se de fato existe preocupação com os rumos da educação e se há consciência quanto à força revolucionária da arte - não há mais o que dizer a não ser que a arte deve invadir a escola.

\section{4) A ciência e a correlação entre distintas áreas do conhecimento}

As ponderações apontadas no item anterior permitem à análise progredir para que seja possível enfrentar alguns questionamentos extremamente pertinentes: de que modo, portanto, a arte poderia contribuir efetivamente com a área de educação? Como seria possível efetivar a correlação entre estas distintas áreas do conhecimento de modo que se enriqueçam mutuamente? Para que seja possível responder a estas questões, seria necessário, antes, questionar se existe algum objeto de estudo que seja estritamente pertencente à área da educação. Se sim, qual? A escola, o professor, o aluno, a didática, a prática de ensino? Mas então qual seria o método que melhor se aplica à investigação de fenômenos que parecem ser próprios à educação e à escola?

Colocadas estas questões vale considerar que por mais que a educação tenha alguns objetos característicos, ela não dispõe de métodos específicos para compreensão dos fenômenos escolares. Por isso, necessita tomar de empréstimo métodos de investigação oriundos de outras ciências, como por exemplo a psicologia, a sociologia, a história, a economia, a administração e suas associações. Desse modo, vale ponderar que a associação de distintas áreas do conhecimento incorre em implicações positivas e negativas: Se por um lado a associação entre áreas diferentes permite aprofundar o conhecimento acerca dos fenômenos educacionais e escolares, por outro, torna a educação uma área permeável uma vez que a investigação dos fenômenos escolares realizados por outras ciências não necessariamente traz avanços específicos para a área de educação.

Para se aproximar do rigor científico, portanto, resta à educação coligar-se à outras áreas para fim de produzir conhecimento científico. Isso, significa dizer que por não ter objeto

\begin{tabular}{|l|l|l|l|l|}
\hline Q Rovista Dialectus & Ano 9 & n. 19 & Agosto - Dezembro 2020 & p. 149 - 161 \\
\hline
\end{tabular}


de estudo ou métodos específicos, a educação não se constitui como ciência. E justamente por não conseguir alçar-se como ciência com objetos, métodos e produção de conhecimento que lhe seriam próprios, ou seja, por não conseguir constituir-se como ciência, a educação parece estar a cada dia mais encerrada no funcionamento rígido e normativo das suas práticas, instituições e problemáticas encerradas em si mesmas e, por isso, como tendência, acaba mais por ceder espaço para aplicação das outras ciências do que a enriquecer-se da interação com elas. Esse processo, ao invés de tornar a educação uma disciplina do conhecimento, acaba por caracteriza-la apenas como campo fértil para aplicação de outras ciências. Isso significa dizer que se por um lado a junção de distintas áreas do conhecimento pressupõem benefício mútuo, esse propósito de enriquecimento conjunto nem sempre acontece com a educação.

Ora, mas se adotarmos os apontamentos tecidos nos itens anteriores que afirmavam ser a arte é um grande canal de desenvolvimento das potencialidades humanas, por que razão o desenvolvimento das potencialidades humanas não poderia ocorrer na escola ou em conjunto com a escola? Neste ponto reside a contradição. Muitas vezes observa-se que o que deveria acontecer na escola tende a não acontecer.

O trabalho com arte, além de proporcionar a criatividade, pressupõe que as atividades desenvolvidas sejam fruto da expressão livre e autêntica e, de modo geral, estes são os atributos que deveriam ser promovidos na instituição escolar. Mas, ao contrário, o trabalho com arte na escola, quando não suprimido a priori pelo próprio funcionamento burocrático da instituição, acontece de modo forçado: é delegado à exclusividade da disciplina de educação artística que, dentre outras tarefas comemorativas anuais, é encarregada de confeccionar com os alunos o coelho da páscoa com enfeites de macarrão.

Além destes exemplos, também é notável a inabilidade da escola no trato com os objetos da cultura com suas inúmeras investidas para tornar acessível por meio da deformação os clássicos culturais produzidos pela humanidade: atribuir letras às melodias eruditas para que seja mais fácil de memoriza-las, substituir a leitura dos clássicos da literatura por suas paródias simplificas, dentre outros exemplos aterrorizantes. Isso posto, é importante frisar aqui que não se trata de restringir o acesso à cultura, mas alertar que tornar a cultura acessível por meio de paródias deformadas pode ser tão prejudicial quanto à falta de acesso.

Frente a esse triste panorama escolar que converte o potencial da arte em alegoria comemorativa de não-sei-quê, urge ao laborioso processo de investigação científica produzir reflexões críticas sobre as formas mais apropriadas para promover uma educação de qualidade de modo que ela seja capaz de promover o desenvolvimento das potencialidades humanas. Para

\begin{tabular}{|l|l|l|l|l|}
\hline Q Rovista Dialectus & Ano 9 & n. 19 & Agosto - Dezembro 2020 & p. $149-161$ \\
\hline
\end{tabular}


isso, ao invés de imaginar que a escola automaticamente promova como que por osmose o desenvolvimento das potencialidades humanas, é preciso antes, questionar primeiro se esta afirmação é verdadeira e, na sequência, é preciso questionar de que ou quais modos ou alternativas seriam possíveis para tornar afetiva essas ambições.

Conclusivamente, este paradoxo, que pela crítica reflexiva procura vias para livrarse de interpretações ingênuas, ao mesmo tempo que permitiu o aprofundamento das áreas de acordo com suas especificidades, acarretou a cisão histórica do conhecimento, uma vez que, porque parcelares, as distintas disciplinas beneficiam-se enquanto padecem mutuamente desta cisão. Por esta razão é fundamental indagar, desde início, se existe de fato algum objeto de estudo que seja estritamente pertencente à área de educação, se ela por si só é capaz de compreender os fenômenos em sua complexidade, ou, se fica à cargo da educação aceitar de bom grado a influência das disciplinas parcelares como forma de proporcionar a expansão dos horizontes da educação a fim de possibilitar a investigação mais apurada de um determinado fenômeno ou objeto de estudo.

Como uma instituição que faz a mediação entre cultura e indivíduo por intermédio da formação, é favorável à educação beneficiar-se do conhecimento historicamente acumulado entre distintas disciplinas tais como a sociologia, a psicologia, a filosofia, a arte e demais áreas que possam contribuir com o desenvolvimento das potencialidades do indivíduo pois, a rigor, são as próprias limitações impostas pela composição restrita do campo educacional que impulsionam pesquisas para caminhos que extrapolam os limites da área de educação. Não por acaso, um dos mais significativos jargões educacionais em voga da atualidade impulsiona estudos científicos que tomam por base o conceito de interdisciplinaridade numa tentativa incansável de tentar rejuntar a todo custo e das mais variadas formas os fragmentos do todo conceitual que algum dia foi entendido como conhecimento. Em linhas gerais, os reagrupamentos disciplinares que a escola se esforça em defender atribui à interdisciplinaridade a tarefa de combater a cisão histórica do conhecimento que há tempos vem fracionando, especializado, parcelando o saber.

\section{5) Notas para uma educação estética da humanidade}

Bom, parece ter ficado evidente que um dos problemas centrais que compõem esta análise reflexiva corresponde a crítica acerca do empobrecimento generalizado da formação e seus desdobramentos acarretados pela forma de organização da cultura e vice-versa. À guisa da

\begin{tabular}{|l|l|l|l|l|}
\hline Q Rovista Dialectus & Ano 9 & n. 19 & Agosto - Dezembro 2020 & p. $149-161$ \\
\hline
\end{tabular}


necessidade sintética de algumas notas conclusivas, foi possível observar que se a livre fruição dos sentidos tem sido negada pelo conteúdo e forma pela qual a cultura e a economia se manifestam, já não é mais possível ignorar alguns alertas claros: a) a cultura afirmativa enfatiza o acesso aos bens da cultura ao mesmo tempo que veta essa possibilidade no plano real, b) o cultivo do espírito é mais uma das inúmeras facetas do privilégio burguês, c) as características reducionistas dos estímulos produzidos vêm reduzindo historicamente as possibilidades de percepção sensível dos seres humanos, d) o contato com bens culturais empobrecidos além de causar a regressão dos sentidos pode acabar também acarretando o estabelecimento de relações sociais pautadas pela frieza. Arroladas essas reflexões, considera-se salutar rememorar que o estabelecimento de relações sociais pautadas pela frieza e pela organização material de existência maculou a história da humanidade com exemplos nefastos catastróficos.

É nesse ínterim, portanto, como proposta alternativa possível, que surge então a aposta no caráter formativo e transformador da arte. Nessa linha de raciocínio, portanto, serão adicionados mais alguns elementos teóricos para fim de enfatizar a reflexão, uma vez que a fruição da beleza na arte corresponde a um valor capaz de promover a sensibilidade e fazer a beleza aparecer: "A qualidade sensorial imediata da beleza remete imediatamente à felicidade no plano dos sentidos". (MARCUSE, 1997, p. 114). O perigo da beleza é que ela faz fruir o ideal de felicidade controlado pela sociedade. Ela escancara a todos o que é negado à maioria. Ela invade de contrabando a sensibilidade anestesiada pela cultura.

A beleza ideal constituía a forma em que se podia expressar o anseio e fruir a felicidade; assim a arte se tornaria um mensageiro que anuncia uma verdade possível. A estética clássica alemã aprendeu a relação entre beleza e verdade na idéia de uma educação estética da humanidade. (MARCUSE, 1997, p.116).

Ao anunciar uma verdade possível, a arte pode ser entendida como uma conexão entre ideais cooptados e realidade objetiva. Assim, a estética pode aproximar - e também tencionar - a relação entre real e ideal. A questão apontada por Marcuse enfatiza que o problema não está na cultura em si, mas em seu caráter afirmativo, que tende a legitimar e manter o existente como norma.

Este é o traço mais conspícuo da ambivalência dos ouvintes em relação à música popular. Eles defendem as suas preferências de qualquer imputação de que sejam manipuladas. Nada é mais desagradável do que confessar a dependência. A vergonha despertada pela acomodação à injustiça proíbe a confissão do envergonhado. Por isso eles voltam o seu ódio antes contra aqueles que apontam sua dependência do que contra aqueles que apertam as suas algemas. (ADORNO e SIMPSON, 1986, p.143).

\begin{tabular}{|l|l|l|l|l|}
\hline Qevista Dialectus & Ano 9 & n. 19 & Agosto - Dezembro 2020 & p. $149-161$ \\
\hline
\end{tabular}


O espaço para o desenvolvimento e apogeu de uma cultura afirmativa que tem como norte o ajustamento às normas sociais pré-estabelecidas só foi possível no âmbito de uma sociedade impregnada por um sistema econômico baseado na reprodução material da vida, no qual não há espaço para o cultivo do espírito. Se as instituições que deveriam promover as potencialidades do indivíduo não têm cumprido seu papel e, mais, se for levado em conta que essa problemática escamoteia o perigo de uma tragédia iminente, o que urge fazer, portanto, é promover reflexões e ações que permitam explorar possibilidades, atividades, experiências e propostas formativas que promovam a sensibilidade, a reflexão e a interação com a cultura de modo que estas investidas impactem e capacitem as potencialidades perceptivas e sensíveis humanas como norte para a pacificação da existências mesmo em face das condições objetivas que a dificultam. Nesses termos, o potencial formativo da arte e a dimensão política da dimensão estética são indícios que justificam a necessidade de dar ênfase ao caráter progressivo e revolucionário de uma educação estética da humanidade.

\section{Referências}

ADORNO, T. W. Teoría de la pseudocultura. In: ADORNO, T. W; HORKHEIMER, M. Sociológica. Traducción de Víctor Sánchez de Zavala. Madrid: Taurus, 1966.

ADORNO, T. W.; SIMPSON, G. Sobre a música popular. In: COHN, G. (Org.). Theodor W. Adorno: Sociologia. São Paulo: Ática, 1986,115-143.

ADORNO, T. W. O fetichismo na música e a regressão da audição. In: Textos escolhidos / Theodor W. Adorno (1903-1969). Consultoria: Paulo Eduardo Arantes, Tradução: Zeljko Loparic. São Paulo: Nova Cultural, 1996.

BENJAMIN, W. Magia e técnica, arte e política: ensaios sobre literatura e história da cultura. Tradução: Sérgio Paulo Rouanet. São Paulo: Brasiliense, 1994.

HORKHEIMER, M. e ADORNO, T. W. A Indústria cultural: o iluminismo como mistificação das massas. In: Indústria cultural e sociedade. Rio de Janeiro: Paz e Terra, 2011, 7-74.

MARCUSE, H. Sobre o caráter afirmativo da cultura. In: Cultura e sociedade. São Paulo: Paz e Terra, 1997, 89-136. (Vol. 1).

MARCUSE, H. Comentários para uma redefinição de cultura. In: Cultura e sociedade. São Paulo: Paz e Terra, 1998, 153-175. (Vol. 2).

\begin{tabular}{|l|l|l|l|l|}
\hline Q Povista Dialectus & Ano 9 & n. 19 & Agosto - Dezembro 2020 & p. $149-161$ \\
\hline
\end{tabular}

